\title{
Innovation and Entrepreneurship in China
}

\author{
M.S. Reshetnikova ${ }^{1}$
}

\begin{abstract}
:
China has recently started a rapid transition to a new economic development phase which is based on high-tech production and national breakthrough technologies.

The reason for this transformation of the innovation strategy lies in scaling innovative system by involving small and medium-sized enterprises (SME). The Government addresses business angels and private venture capital funds to finance SMEs.

The aim of the study is to identify and assess changes in the innovative entrepreneurial sector of China's economy, and also analyze the impact of these changes on the dynamics of innovative entrepreneurship activity in the country. The methodical basis of the article were the dialectical and systematic approaches to the study of economic processes, based on the use of methods of comparison and classification. The analysis showed that in total, by 2016, the Chinese Government makes all-out effort to stimulate mass innovation entrepreneurship.
\end{abstract}

The result of such significant support was not only large-scale inclusion of small and medium-sized businesses in $R \& D$ activities, but also the development of new innovative structures that led to certain changes in the landscape of China's NIS.

The research helped to expose both the existing problems of regional innovation inequality and general trends in innovative entrepreneurship in China.

Keywords: China, venture capital, growth, entrepreneurship

JEL Classification: O31, O32, O38, O53

\footnotetext{
${ }^{1}$ Peoples' Friendship University of Russia (RUDN University), reshetnikova_ms@rudn.university
} 


\section{Introduction}

Rapid economic growth has enabled China to become one of the key players in the world economy. Chinese government made this come true by consistently implementing its innovative strategy for the national economy development. The success of this strategy is obvious. By 2010, China's NIS became one of the largest in the world (Reshetnikova, 2016). In terms of scale and scientific equipment, it has approached the leaders of innovative growth. However, the feedback that Chinese economy gets from the innovative system does not allow it to step up to a new level of production. It will be impossible to reach this target without transforming the NIS in China to a self-developing state.

The purpose of the article is to identify and assess the changes in the landscape of the innovative entrepreneurial sector in China's economy and analyze the impact of these changes on the dynamics of innovative entrepreneurship activity in the country.

\section{Methods}

The methodological basis of the research project lies in dialectical and systematic approaches to the study of economic processes through comparison and classification. The information base lists annual reference books published by official Chinese institutions, articles and monographs of Chinese, Russian and Western economists. This work is an independent scientific research, the main provisions of which are developed by the author independently.

\section{Modern transformation of innovative entrepreneurship landscape in China}

In 2004 the NIS environment in China was based mainly on technology parks and high-technology zones (TP and HTZ). By 2015 their total production of high-tech products reached 13\% of China's GDP (Reshetnikova, 2016; Orszag, 2014; Schaaper 2009; Bibarsov et al., 2017; Bashmakov et al., 2015; Breckova 2016; Frank et al., 2016). The reason for this lies in consistent state strategy for the development of corporate innovation activity.

However, starting from 2009, this strategy undergoes certain transformations aimed at stimulating innovative entrepreneurship through increasing the innovative activity of SMEs. The government program "Mass entrepreneurship, universal investments" (2009) with an annual financing of $\$ 6.5$ billion initiated this process. In addition to this program, in 2010 the government launched the SBIR (The Small Business Innovation Development and Research) program. It serves to attract private businesses to solve specific scientific and technical problems faced by 10 largest federal ministries and national agencies. Its funding is $2,5 \%$ based on their own budget supporting R\&D in SMEs. By 2016, the SBIR program has allocated more 
than $\$ 42$ billion to support 28410 technology projects promoting modernization and independent innovation in SMEs (Reviews of Innovation Policy, 2017).

In total, by 2016 , the Chinese Government spent more than $\$ 56$ billion to stimulate mass innovation entrepreneurship (Reviews of Innovation Policy, 2017). Such significant support resulted not only in large-scale involvement of small and medium-sized businesses in R\&D activities, but also in the development of new innovative structures that led to certain changes in the landscape of China's NIS. By 2016 business incubators and clubs of technological creativity (hackerspaces, makerspaces), directly related to them, have significantly strengthened their positions, both in quantity and in terms of economic efficiency. In the financial sector, business angels and small venture investment funds, focused on financial and legal support, primarily SMEs, work at an increasing scale and get more successful.

\subsection{Drivers of entrepreneurship in China}

Starting from 2013, the growth rates of newly registered SMEs working in the innovation sector amounted to 23,4\% per year. By 2016 China had 19,1 million companies in R\&D. The total number of specialists employed exceeded 164 million people. Authorized capital of these companies was estimated at about \$14,5 trillion, which corresponds to $52,9 \%$ of the total authorized capital of SMEs in the country. Innovative small and medium-sized businesses can't develop at such a large-scale and so rapidly without an appropriate modern research and production infrastructure. Today business incubators and hackerspaces traditionally provide crucial assistance in organizing research for private enterprises. The latter, defined as laboratories with open (paid or free) access, provide innovative SMEs with infrastructure, professionals and expensive research, analytical and measuring equipment. Hackerspaces appeared in Europe in the late 90's were developed and got hardware design at the Massachusetts Institute of Technology (USA).

Hackerspace in 2016 features a scientific workshop, a laboratory equipped with modern research and measurement complex "Fablab", that is a part of the world research analytical network (Statistics of University's Industry in China, 2017). The first public workshop - hackerspace opened in the province of Shenzhen in 2010. In 2016, their number approached 47 (Fig. 1). It's worth pointing out that hackerspaces are geographically located near business incubators. In addition, these new elements in the landscape of China's innovative entrepreneurship depend upon each other in their development. Obviously, their joint R\&D activities contribute to the economic success of innovation projects and build innovation ecosystem. The world's largest hackerspace is in Beijing. Its area is $16500 \mathrm{~m}^{2}$. Beijing and eastern regions overall are in the lead of regional innovation competition. This area hosts innovation projects that are the biggest not only in China, but in the rest of the world as well. In 2016 alone, the Beijing high-technology zone registered 18,000 scientific and technological enterprises, and more than 10,000 high-tech enterprises, which accounted for $25 \%$ and $20 \%$ country production volume respectively. By 2016 Changzhou has been hosting more than 468,000 successfully operating SMEs, that 
received the state status "Innovative Enterprise" (OECD Reviews of Innovation Policy, n. d.).

Figure 1. Dynamics of national incubators development in China

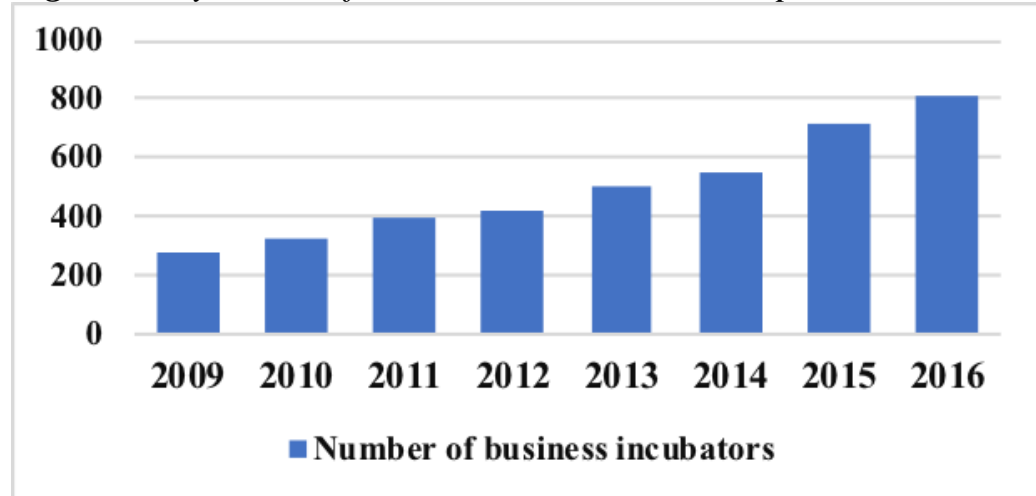

Sources: Compiled by the author based on web-resource: "Features of innovation and entrepreneurship activities in China" China PRO.

That is why there are more hackerspaces in the eastern and south-eastern region of China. Such inequality in innovation within the regions certainly has a negative impact on the country's regional economic development, despite all the efforts of the central and provincial governments, and this makes the country's innovation profile inhomogeneous.

\section{Transformation of the investment market}

The strategy of the central and regional government in China aimed at strengthening the innovative entrepreneurship has undoubtedly scored a success. This success could not be reached without the Government's efforts aimed at improving financial support for innovative entrepreneurship activity of SMEs. First, with the transition to market methods of financial support the Chinese government significantly strengthened the position of public investment (Table 1). By the end of 2015, China had 780 investment funds with a capital volume of over $\$ 330$ billion, which is higher than that of the innovation leaders.

Table 1. Public investment in China

\begin{tabular}{|l|l|l|l|l|l|}
\hline & 2012 & 2013 & 2014 & 2015 & 2016 \\
\hline Targeted volume of funds, MM. USD & 38,0 & 38,4 & 107,6 & 330 & 450 \\
\hline Volume of attracted capital, MM. USD & 20 & 24 & 90,8 & 170 & 300 \\
\hline Number of funds & 256 & 320 & 400 & 780 & 812 \\
\hline
\end{tabular}

Sources: Compiled by the author based on web-resource: The Ministry of Commerce of the PRC.

Innovative SMEs got additional incentive to develop in 2014, due to a change in the strategy, namely, venture capital moving towards start-ups in the early stages of development. In 2015 alone, 15,857 innovative SMEs got public investments in the 
amount of $\$ 900$ million from (Statistics of University Industry in China, 2016). Increasing innovative activity small and medium business boosted the development of private venture capital market in China. In early 2015, the State Council issued a decree on scaling up venture investment in the country's economy, that shaped business angel investment market and private venture capital in China.

\section{1 Business angel market in China}

The Chinese market of angel investment started only in 2015, now plays an increasingly noticeable role. There are several reasons for such rapid increase in angel investment in China. The first of them lies in rapid development of high-tech industries, such as IT, biotech and alternative energy engineering. This resulted in a significant increase in the amount of wealthy people in China, the so-called HNWI (High-net-worth individual) - individuals with liquid assets of over \$1,6 million. In 2016, the number of HNWI in China was more than 1,2 million people (OECD Science, 2016). The total amount of private capital in 2016 was more than $\$ 20$ trillion.

The second reason is the government policy during the transition of China's economy to the "New Form", which led to lower growth rates and decreasing return on assets. This worked as an incentive to expand investment portfolios with risky projects and, above all, start-ups in the innovation sector. More than $36 \%$ of Chinese private investors surveyed in 2016 were willing to increase their investments in high-tech SMEs (OECD Science, 2016).

Analyzing the statistical data on the angel investment market growth rates in China, one can single out its specific national characteristics. First, there is definite transformation towards institutionalization. Many business angels unite in clubs, that allows them to diversify risks and investment portfolios.

In early 2016, China registered more than 350 business angel clubs (150 of them were in active investing). The total volume of their assets exceeded $\$ 9$ billion (Fig. 2). According to reports from Tsinghua University, in 2016, in China 2780 angel transactions were registered in high-tech sector of SMEs alone, with an overall total investment of about $\$ 1,5$ billion - twice as much as in 2015 (The Ministry of Commerce in the PRC, 2016). The fact is that the key investment is observed in IT and telecommunication industries. Investment in these areas exceed $70 \%$ of the total volume (Figure 3). The regional activity of the angel investment market is also predictable. Traditionally, Beijing, Shanghai and Shenzhen remain as the leaders. Only in the first half of 2017, $\$ 0,65$ billion was invested in start-ups of SMEs in the Beijing industrial zone, which accounts for $43,5 \%$ of all transactions in the country. 
Figure 2. Dynamics of business angel investment in China

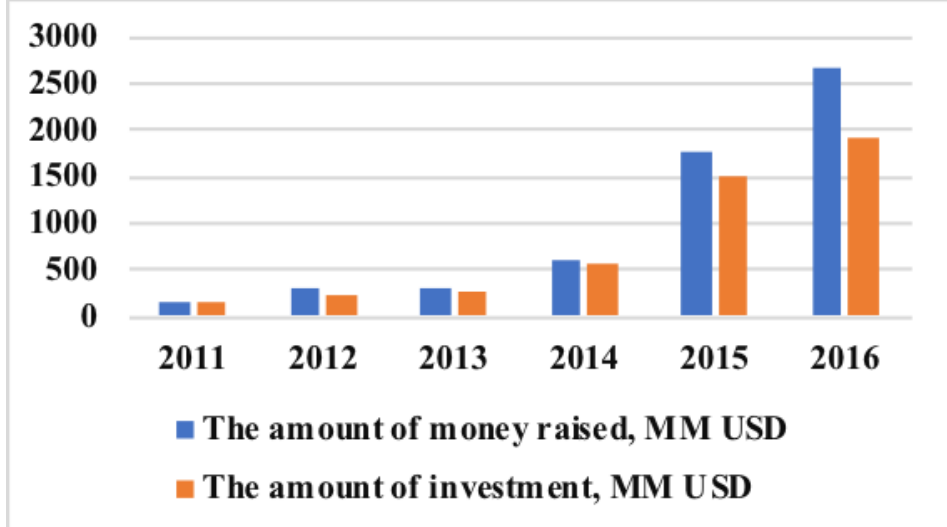

Sources: Compiled by the author based on web-resource: OECD Science, Technology and Innovation Outlook 2016.

Figure 3. Distribution of business angel investments by industries in China

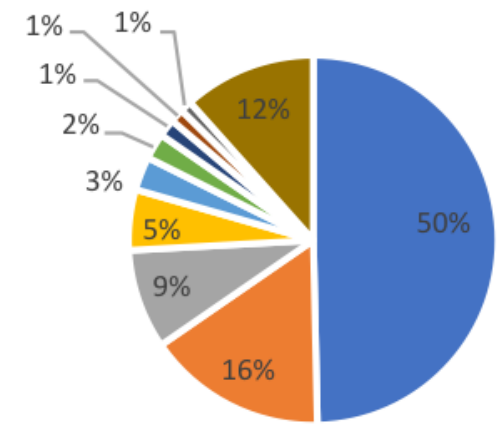

$$
\begin{aligned}
& \text { - Internet } \\
& \text { - Telecommunications } \\
& \text { " IT } \\
& \text { " Finance } \\
& \text { - Entertainment } \\
& \text { - Boit ech/Health } \\
& \text { - Engineering }
\end{aligned}
$$

Sources: Compiled by the author based on web-resource: "Features of innovation and entrepreneurship in China" China PRO.

\subsection{Venture capital in China}

Today, China's private venture represents a complex multi-step regional system. Thus, according to the data presented in Tsinghua University report, 2016 witnessed China to have more than 8000 successfully operating active investment agencies, with assets of more than $\$ 750$ billion. There are more than 28000 successfully operating venture funds (more than 1000 of them are in the seed stage) with assets of $\$ 700$ billion. In 2015597 new funds were created, that focused on the mainland of China and raised capital of $\$ 30$ billion (The Ministry of Commerce in the PRC, 2016; Global Innovation Investment report, 2016).

Key venture investments in China, namely more than $50 \%$ of them, goes to developing Internet solutions, IT and telecommunications technologies (Figure 4). 
Figure 4. Top-10 major industries for venture capital investment in China

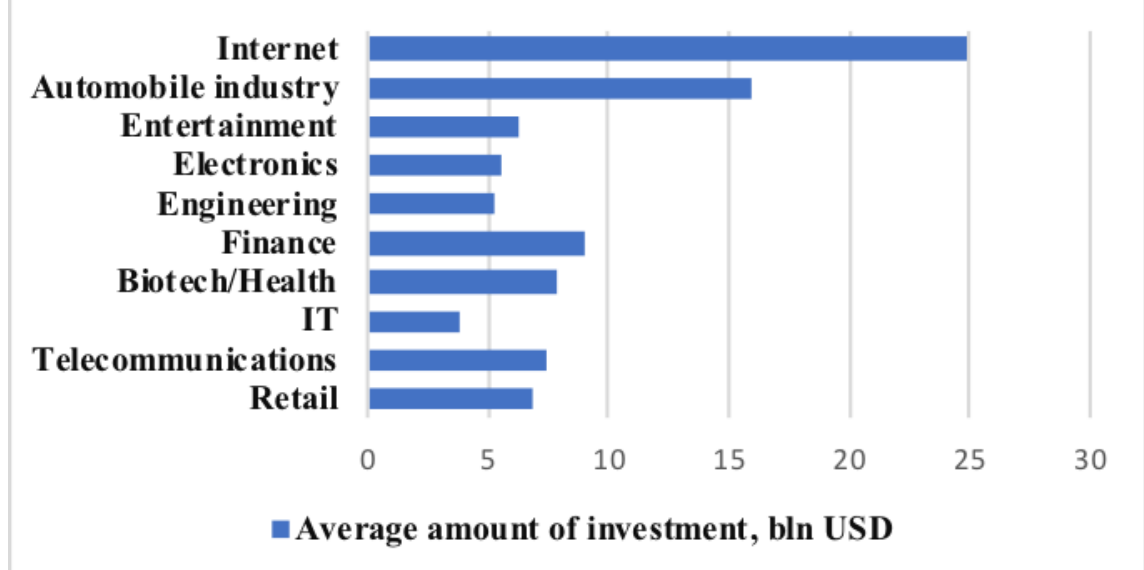

Sources: Compiled by the author based on web-resource: "Features of innovation and entrepreneurship in China" China PRO.

Consistent government policy aimed at enhancing the investment attractiveness of innovative entrepreneurship brought about significant success. This shows not only a significant increase in the volume of investment, but also changing distribution throughout the stages of project maturity. Starting from 2015, the number of investment transactions at seed stage amounted up 22,3\%, and transactions at early stage $-32,6 \%$ of the total venture transactions (Table 2). In comparison with 2014 the investment growth was $11,5 \%$ and $21 \%$, respectively (The Ministry of Commerce in the PRC, n. d.).

Table 2. Distribution of venture investments by stages of project maturity in 2015

\begin{tabular}{|l|l|l|l|l|}
\hline $\begin{array}{l}\text { Start-up } \\
\text { phases }\end{array}$ & $\begin{array}{l}\text { Amount of } \\
\text { deals }\end{array}$ & $\%$ & $\begin{array}{l}\text { Investment, MM. } \\
\text { USD }\end{array}$ & $\begin{array}{l}\text { Average transaction } \\
\text { volume, MM. USD }\end{array}$ \\
\hline Seed & 876 & 23,4 & 23,55 & 0,03 \\
\hline Early & 1122 & 32,6 & 52,84 & 0,05 \\
\hline Growth & 963 & 28,0 & 61,82 & 0,07 \\
\hline Exit & 484 & 14,0 & 55,69 & 0,123 \\
\hline Total & 3445 & 100 & 194 & \\
\hline
\end{tabular}

Sources: Compiled by the author on the basis of web-resource: OECD Reviews of Innovation Policy. China.

Analysis of the data presented in Table 2 shows that projects in seed and early stages are of greater interest to investors. This is the reason for them to prevail in the total number of transactions. According to disclosed data on investment volume, investments into seed and early stage projects in 2016 reached 60,2\% of the total volume of venture investments. At the same time, the volume of investments at these stages is lower than that of later stage projects.

Having analyzed current investment market in China, the author asserts that starting from 2014 the country has witnessed accelerated transformation towards increasing 
private investment. Public investment undoubtedly still play a decisive role in stimulating innovative entrepreneurship of SMEs. At the same time, starting from 2015,--private investments play increasingly big role in supporting the innovative development of the Chinese economy. These investments differ in form and in scale. The dynamics of quantitative growth and the scale of business angels, private venture funds and agencies, allow the author to assert that they will soon take a worthy place in the landscape of China's NIS.

\section{Discussion of Research Findings}

By 2010, China's NIS is one of the largest in the world. In terms of scale and scientific equipment, it has come close to the leaders of innovative growth. The state program of "Mass entrepreneurship, comprehensive investments" launched in 2010 gave an acceleration to the involvement of SMEs in innovative production. One of the successful results of this program is the rapid development of new organizational technical and financial forms that stimulate and support their innovative activity. In Chinese realities they are hackerspaces, business incubators, business angels and venture capital focused on innovative SMEs. Development trends of these new elements in the landscape of China's innovative entrepreneurship are clearly interdependent, which was shown by the study. Innovative inequality in the regions, despite all the efforts of the central and provincial governments to overcome it, certainly has a negative impact on the country's economic regional development and makes its innovative profile uneven.

Nevertheless, the research shows that the strategy of the central and regional governments of China to strengthen the activity of innovative entrepreneurship has brought significant success. First, the Chinese government, having switched to market methods of financial support, significantly strengthened the positions of public investment- An additional incentive for the development of innovative SMEs was in 2014 due to a change in the strategy of public investment, namely, the movement of venture capital towards start-ups in the early stages of development. Born in 2015, the Chinese market of business angel investments today plays an increasingly noticeable role. The study showed that the following reasons contributed to this:

1. The significant growth of private investors, the so-called HNWI (High-net-worth individual), due to a period of rapid development of high-tech industries.

2. Government policy, namely, the transition of China's economy to the "New Form", one of the components of which is a slowdown in growth and a decrease in return on assets.

The analysis revealed certain national characteristics of business angels' investments market in the PRC, namely, the transformation towards institutionalization. Many business angels are united in clubs, which allow diversifying risks and diversifying a set of investment objects. 
After analyzing the current investment market in China, the author states that starting from 2014, there is an accelerating transformation in the direction of increasing private investment. Dynamics of growth in the number and scale of business angels, private venture funds and agencies, allows the author to assert that they will soon take a worthy place in the landscape of China's NIS.

The study showed that by pursuing the path of high-tech regional innovative clusters growth, China is successfully approaching the task "to become an innovativeoriented country until 2020". However, insufficient funding of S\&T research at the entrepreneurial level is hampered by China as a beneficiary of innovative growth. Private investors do not hurry to invest in scaling up breakthrough national technologies and scientific research. Buying technologies and research results from the leaders of innovation growth now is increasingly difficult.

One of the ways to overcome this problem can be the growing global character of modern science. The policy of openness allowed China to become one of the beneficiaries of the world economy growth. Now, adapting the most advanced achievements of innovation, it strives to become a beneficiary of innovative growth. The scientific cooperation of China with the innovative leaders was not considered in this research work, which is a drawback of this article and determines the goals for further study of the Chinese experience in the development of innovative entrepreneurship.

\section{Conclusion}

The analysis of modern innovative entrepreneurship landscape in China allows the author to draw certain conclusions. It is obvious that the state innovation strategy, initiated in 2006 to increase the role of small and medium-sized businesses in the innovative sector of the economy brings positive results. Its role in research and development activities, as well as in financing R\&D and launching new high-tech industries has grown significantly.

The analysis of the presented data allows the author to draw a conclusion that the Chinese economy has started the transition to a new technological level. This process is confirmed by the drop in economic interest of businesses in low-cost labor-intensive production technologies.

\section{References:}

Features of innovation and entrepreneurship in China. China PRO. Date Views 01.03.2018 http://www. chinapro.ru

Bashmakov, A.I., Popov, V.V., Zhedyaevskii, N.D., Chikichev, N.D. and Voyakin, A.E. 2015. Generic Heurorithm of Innovation Management from Generating Ideas to Commercialization. European Research Studies Journal, 18(4), 47-56.

Bibarsov, K.R., Khokholova, G.I. and Okladnikova, D.R. 2017. Conceptual Basics and Mechanism of Innovation Project Management. European Research Studies Journal, 20(2B), 224-235. 
Breckova, P. 2016. Family Business in the Czech Republic. European Research Studies Journal, 19(4), 3-16.

Frank, V.E., Mashevskaya, V.O. and Ermolina, V.L. 2016. Innovational Mechanism of Implementation of Cluster Initiatives in Business. European Research Studies Journal, 19(1), 179-188.

OECD Reviews of Innovation Policy. China. www.oecd.org/sti/inno/oecdreviewsofinnovationpolicychina.htm

OECD Science, Technology and Innovation Outlook 2016. www.oecd.org/sti/oecd-sciencetechnology-and-innovation-outlook-25186167.htm.

Orszag, P.R. 2014. Private Companies Are Driving China's Growth. www.bloomberg.com/view/articles/2014-10-14/private-companies-are-drivingchina-s-growth.

Reshetnikova, M.S. 2016. Analysis of state instruments for modernization and innovation in high-tech sectors of the economy. Modern Science. Actual problems of theory and practice. Economics and Law, 9, 27-33.

Reviews of Innovation Policy. China. Synthesis Report. 2007. www.oecd.org/sti/inno/39177453.pdf

Schaaper, M. 2009. Measuring China's Innovation System: National Specificities and International Comparison. www.oecd.org/sti/42003188.pdf.

Statistics of University Industry in China. Ministry of Education, Center for S\&T Development. www.edu.gov.cn.

The Ministry of Commerce in the PRC. www.english.mofcom.gov.cn/. 